\title{
A representação do indígena no discurso de estudantes de Psicologia: possíveis impactos sobre a escuta do sofrimento psíquico indígena
}

\author{
The representation of the indigenous in the discourse of \\ Psychology students: possible impacts on the listening of \\ the indigenous psychic suffering
}

\author{
Rafael Filter Santos da Silva ${ }^{1}$ \\ Rosa Maria Castilhos Fernandes ${ }^{1}$ \\ Rejane Nunes de Carvalho ${ }^{1}$
}

DOI: http://dx.doi.org/ 10.20435/tellus.v19i40.615

\begin{abstract}
Resumo: Este artigo é um dos frutos do projeto de pesquisa documental "Contribuições para afirmação dos direitos indigenistas no ensino superior: uma experiência de extensão e pesquisa na UFRGS". Focamos nas respostas dos participantes dos seminários "O que é ser índio?", realizados no curso de Psicologia da UFRGS, refletindo acerca das representações sobre os indígenas e os possíveis impactos na escuta do sofrimento psíquico desses coletivos. A análise do conteúdo das respostas mostra a persistência de representações coloniais sobre o indígena, as quais podem ser prejudiciais à escuta do sofrimento psíquico indígena feita por um não indígena. Embora haja respostas que demonstrem maior sensibilidade às diferenças étnicas, constatamos a necessidade de ampliação das oportunidades de encontros entre as diferenças, pois o contato intercultural é um caminho para desconstruir uma escuta colonizadora e fazer da Psicologia uma ferramenta útil para diferentes raças e etnias.
\end{abstract}

Palavras-chave: indígena; representação; escuta.

Abstract: This article derives from a documentary research project, "Contributions for affirmation of indigenous rights in higher education: an extension and research experience at UFRGS". We focused the responses of the participants of the seminars "What is being an Indian?" occurred in the UFRGS Psychology undergraduate course. We reflected on the representations about the indigenes and the possible impacts on listening of psychic suffering of these collectives. The analysis of the content of the answers shows the persistence of colonial representations about the indigenous, which can be harmful to the

${ }^{1}$ Universidade Federal do Rio Grande do Sul (UFRGS), Porto Alegre, Rio Grande do Sul, Brasil. 
listening of the indigenous psychic suffering made by a non-indigenous person. Although there are answers that show greater sensitivity to ethnic differences, we notice that is necessary to increase opportunities for encounters between differences, because intercultural contact is a way to deconstruct a colonizing listening and make Psychology a useful tool for different races and ethnicities.

Keywords: indigene; representation; listening.

\section{INTRODUÇÃO}

"É ser uma pessoa pertencente a uma cultura mais ligada com a natureza, mas é muito difícil para mim tentar definir isso" (FERNANDES, 2017). Essa é uma dentre as tantas respostas obtidas durante a atividade de extensão realizada pelo Grupo de Acolhimento ao Estudante Indígena (GAIn), denominada "O que é ser índio?". A pergunta-título era o gatilho para o início do diálogo entre estudantes indígenas, servidores da universidade e estudantes fógs ("não indígenas" na língua kaingang) da Universidade Federal do Rio Grande do Sul. Sabíamos do uso problemático do termo "índio" para denominar a ação, mas fora uma escolha dos próprios estudantes indígenas, como recurso léxico disparador dos seminários, tendo em vista o uso corriqueiro desse vocábulo entre a população brasileira.

A atividade de extensão consistia em realizar seminários em forma de roda de conversa nos cursos em que havia estudantes indígenas. O objetivo era contribuir com a defesa dos direitos indigenistas e a afirmação dos estudantes indígenas no âmbito acadêmico. O seminário iniciava-se com a pergunta "O que é ser índio?", a qual era respondida pelos participantes não indígenas individualmente em uma folha. A partir das respostas, os estudantes indígenas falavam sobre seus costumes, suas identidades, seus conhecimentos, suas dificuldades, suas diferenças etc. A representação sobre o "índio" era colocada em debate.

A leitura das respostas coletadas ao longo da atividade de extensão provocou inquietações, as quais deram origem a uma pesquisa documental do tipo qualitativa, intitulada: "Contribuições para afirmação dos direitos indigenistas no ensino superior: uma experiência de extensão e pesquisa na UFRGS". O objetivo foi analisar o conteúdo das respostas para pensar os significados atribuídos pelos estudantes e servidores da UFRGS durante a ação de extensão supracitada desenvolvida pelo GAln, no intento de contribuir com a defesa das ações afirmativas que envolvem a população indígena. O principal documento analisado foi o relatório 
A representação do indígena no discurso de estudantes de Psicologia: possíveis impactos sobre a escuta do sofrimento psíquico indígena

da atividade de extensão (a qual foi desenvolvida de março de 2016 a maio de 2017), que sistematizou todas as respostas à questão: “O que é ser índio?".

O esquadrinhamento das respostas gerou um rol de categorias, separadas a partir de unidades de significado: Natureza; Pertencimento Cultural; Povos Originários; Violação de Direitos e Sofrimento; Resistência; Sujeitos de Direitos. Ao todo, obtivemos 229 respostas documentadas, dentre elas, 31 de alunos/as de Psicologia. Chama-nos a atenção, neste processo de investigação, que é no curso de Psicologia que a compreensão do que é ser índio aparece associada ao "sofrimento" que estas pessoas possam sentir em função da discriminação, da exploração, da violação de direitos, entre outras causas citadas pelos participantes.

Ainda que sucintamente, podemos aferir que a categorização das respostas deu-se da seguinte maneira, conforme a interpretação de seus conteúdos: 1) Natureza: ser índio é possuir saberes e modos de vida associados a uma conexão com a natureza; 2) Pertencimento cultural: ser índio é pertencer a um grupo, ou etnia, com uma cultura diferente da sociedade envolvente brasileira; 3) Povos originários: ser índio é ser parte dos povos originários, considerados os primeiros brasileiros, ou primeiros habitantes do que é o atual território brasileiro; 4) Violação de direitos e sofrimento: ser índio é sofrer violações de direitos, que produzem discriminação e sofrimento; 5) Resistência: ser índio é resistir às opressões e preconceitos; 6) Sujeitos de Direitos: ser índio é ser detentor de direitos específicos, como o direito à terra, às suas culturas e, portanto, aos chamados direitos indigenistas.

Responder tal questão é realmente difícil. Não será encontrada nesse texto a resposta derradeira. Aqui, discutiremos as representações sobre os indígenas que apareceram nas respostas à pergunta "O que é ser índio?" dos participantes dos seminários realizados no curso de Psicologia da UFRGS, um dentre os cursos e espaços onde a atividade de extensão analisada na pesquisa se desenvolveu. Esse recorte enfocado na Psicologia foi o escolhido para compor esse artigo porque dois dos autores são dessa área e sentiram certos desassossegos diante dos conteúdos das respostas de seus colegas.

Assim sendo, a partir de nossa experiência em monitoria e orientação das estudantes indígenas do curso de Psicologia e Serviço Social da UFRGS, como membros do GAIn-UFRGS e pesquisadores, surgiram reflexões sobre como as representações acerca do indígena podem impactar na escuta de seu sofrimen- 
to. Representações fundamentadas na falta de conhecimento histórico e na incompreensão da alteridade podem prejudicar a escuta das demandas indígenas relacionadas com o contato intercultural com a sociedade envolvente, que se caracteriza pelos ideais capitalistas.

Entre os exemplos de sofrimentos indígenas atrelados à universidade, logo, à inserção no cotidiano de uma sociedade regida pela produção e reprodução do capital, pela competitividade e pelo individualismo, estão a angústia, a depressão e a ansiedade relatadas pelos integrantes indígenas do GAln, quadros que alegam não serem comuns em sua cultura. A exigência de adaptação ao funcionamento acadêmico, com exíguas contrapartidas da universidade, de seus funcionários e alunos, cobra uma temporalidade apressada e compassada, assim como uma competitividade individualista. Distantes de um tempo calmo, sem ponteiros; de um espírito comunitário cooperativo; de suas famílias, de seus rituais, entre outros elementos culturais, o sofrimento psíquico gera, em algumas situações, o abandono de disciplinas ou da graduação e o retorno prematuro para a aldeia, além de refletir-se no corpo, contribuindo com o desenvolvimento de problemas de hipertensão, obesidade, entre outros, que são mencionados pelos estudantes.

Além destes apontamentos introdutórios, este artigo está organizado em duas partes. Primeiro, discorremos de maneira sucinta sobre o processo histórico de conformação do GAIn e as adversidades que emergem no território acadêmico por conta do acesso dos estudantes indígenas à educação superior. Na sequência, entramos no objetivo principal do artigo, a saber, refletir acerca das representações presentes nas respostas e a forma como elas influenciam a relação entre não indígena e indígena, em especial no que diz respeito à escuta do sofrimento indígena feita pelo não indígena. Encerramos fazendo algumas colocações acerca da escuta das diferenças indígenas, respaldando-nos em estudos do campo da Psicologia que tratam desta temática.

\section{GAIn: UM POUCO DA HISTÓRIA}

A presença indígena no meio acadêmico foi, por muito tempo, em forma de objeto de estudo, o que pouco ou nada valorizava sua voz. Desde a implementação do sistema de reserva de vagas na UFRGS em 2008/1, cresce a proporção do indígena como sujeito acadêmico que compõe a produção universitária no papel de 
A representação do indígena no discurso de estudantes de Psicologia: possiveis impactos sobre a escuta do sofrimento psíquico indígena

autor, direcionando estudos e expondo outras perspectivas. Tal política educacional está em consonância com a Lei de Cotas (Lei Federal n. 12.711) (BRASIL, 2012).

A reserva de vaga no curso de Serviço Social é um pedido recorrente das lideranças indígenas. Foi por meio da ação de três estudantes indígenas kaingang desse curso que, em 2014, o GAln surgiu. O grupo é uma estratégia de criação de um espaço coletivo de diálogo permanente sobre as necessidades sociais que emergem das vivências destas pessoas na UFRGS, tais como: dificuldades de diálogo com monitorias ou professores orientadores; dificuldades no processo de ensino e aprendizagem referentes à leitura e interpretação de textos; sistematização de conhecimentos; relacionamentos em sala de aula; instrumentos de avaliação diferenciados; entre outros (FERNANDES; AMES; DOMINGOS, 2017).

Todo estudante indígena que ingressa tem direito a ter um professor orientador e um estudante do seu curso como monitor. No entanto, esses aportes muitas vezes se tornam insuficientes para sua permanência. As estudantes indígenas do curso de Serviço Social, perante essa insuficiência, trouxeram uma demanda comum para a professora orientadora e decidiram iniciar um processo de discussão coletiva, tornando a orientação e a monitoria um trabalho de acompanhamento coletivo. O grupo expandiu-se ao longo do tempo, passando a ser frequentado por estudantes indígenas, monitores e professores orientadores de outros cursos, tais como Psicologia, Fisioterapia, Direito, Odontologia etc.

A proposta da realização dos seminários emergiu destes encontros do GAln. Teve como objetivo geral promover reflexões, criando espaços de diálogos interculturais entre os estudantes da UFRGS, monitores e professores, visando ao atendimento das necessidades sociais dos coletivos indígenas no âmbito acadêmico para contribuir com os seus processos de formação, assim como para questionar as epistemologias preponderantes dentro da estrutura universitária.

Os seminários foram transformados em atividade de extensão. Ocorreram em diversos cursos (História, Serviço Social, Pedagogia, Psicologia etc.) e espaços, sendo realizados, inclusive, em formações de servidores da universidade. O conjunto de atividades desenvolvidas nesta extensão e a riqueza das conversações deflagradas encontram-se sistematizados em documentos, relatórios, fotos e vídeos que são importantes experiências que vêm sendo analisadas a partir de um processo investigativo em parte socializado aqui neste artigo. 


\section{O BOM SELVAGEM QUE PODE ATRAPALHAR A ESCUTA: REPRESENTAÇÕES SOBRE INDÍGENAS}

Dizer que o mito do bom selvagem persiste no imaginário social não é uma mentira. O indígena inocente da carta de Pero Vaz de Caminha ([1500]1999) sobreviveu. As ideias surgidas nos debates ocorridos ao longo do auge da colonização das Américas sobre a condição humana em estado de natureza e de civilização ainda povoam as representações de universitários fógs sul-rio-grandenses, que insistem em romantizar os indígenas como seres humanos puros e virtuosos pertencentes à natureza.

A pergunta-título dos seminários rendeu respostas como: "É difícil descrever em uma frase ou palavra, porque envolve complexidade na resposta. Diferentes culturas que tem como base a relação com a terra e a natureza"; "É respeitar todos os modos de vida de uma forma que o 'homem branco' não sabe ver"; "Ser índio é ter uma maior harmonia com a natureza"; "Verdadeiro conhecedor/pesquisador da terra" (FERNANDES, 2017). Nas palavras de não indígenas, o indígena é o ser humano imiscuído na natureza de modo harmônico, o que se depreende que seja uma condição abandonada pelo branco durante seu processo civilizatório. 0 respeito à terra e aos distintos modos de vida compõem a cultura das populações autóctones, confundidas com a noção de primeiros habitantes do Brasil.

O status de população original brasileira aparece em respostas como: "Acredito que isso seja algo difícil de definir e generalizar, considerando a diversidade dos povos indígenas; mas quando penso na palavra 'índio', penso que por serem os primeiros habitantes do Brasil, a sua longa história com esta terra e esta natureza os fazem serem especialmente conectados com as mesmas" (FERNANDES, 2017). O estrangeiro-colonizador, pela ausência de conexão com o território, não respeitaria a natureza, nem mesmo quem ocupou esta área do mundo primeiro, tendo em vista outra resposta: "Ser índio é, muitas vezes, sentir-se um forasteiro indesejado em sua própria casa". Caso pensemos "forasteiro" a partir da perspectiva de Stuart Hall (2013), como alguém cuja identidade está vinculada ao território, mas não é reconhecido pelos demais ocupantes daquele espaço como pertencente àquele território, devido à sua ascendência distinta da etnia dominante, o indígena é um forasteiro, apesar de brasileiro, pois é marginalizado pela sociedade. 
A representação do indígena no discurso de estudantes de Psicologia: possíveis impactos sobre a escuta do sofrimento psíquico indígena

Entretanto, cabe ressaltar que, embora distintas etnias indígenas povoassem o que é o território brasileiro hodiernamente, o Brasil não existia antes do processo colonizador português. As etnias indígenas são consideradas sociedades originárias pela Organização dos Estados Americanos (2016), da qual o Brasil faz parte, possuindo direito originário e imprescritivel às suas terras por ocupá-las desde antes da colonização europeia, porém, se interpretarmos "casa" como o Estado-nação existente, ela foi construída após a independência do país, através de atos e ideias violentas contra as populações não brancas que ocupam o território. Desse modo, eles comporiam os primeiros brasileiros, contudo não seriam os únicos. Brancos e negros também eram parte da população que fundou o Estado de uma maneira intercultural. Apesar das violências, as culturas diferentes trocaram entre si, constituindo uma cultura miscigenada nova no território brasileiro.

Além disso, as alunas indígenas kaingang destacam que não são os donos da terra. Vivem em harmonia e respeito com a terra, usufruindo dela em prol de um bem viver ${ }^{2}$, sem possuí-la como propriedade privada ou explorá-la como um meio de produção capitalista. Daniel Munduruku (2009), filósofo doutor em Educação pertencente à etnia Munduruku, assevera que os indígenas mantêm uma relação amorosa com a Mãe Terra, na qual não são seus proprietários, mas sim seus guardiões, prezando por sua existência. A natureza, por conseguinte, atravessa os saberes e as culturas indígenas, todavia não os torna naturais, ou selvagens, ou espontâneos. A rede de significados que sustenta a cultura de cada etnia foi construída historicamente, à medida que os sujeitos atribuíam sentidos à natureza, distintos dos concebidos pelos não indígenas. O branco interage com a terra, sendo parte da natureza, não obstante a desrespeita corriqueiramente através da selvageria dos processos de produção e reprodução do capital.

2 Conforme a indígena kaingang, Angélica Ninhpryg (2016, p. 27), "O bem viver kaingang pode ser considerado um movimento contra-hegemônico, pois estes modos de vida, modos de existência, vão contra a ordem neoliberal competitiva, que viola os direitos humanos, que discrimina coletivos indígenas, quilombolas, mulheres, entre tantos outros". O bem viver rompe com uma lógica de qualidade de vida baseada nos ideais capitalistas de progresso produtivista, de antropocentrismo, de desenvolvimentismo e de consumismo, não se confundindo com a ideia ocidental de bem-estar. Procura um novo caminho para a vida, diferente do tipo preponderante na sociedade envolvente. O bem viver não quer ser um mero adjetivo para compor novos-velhos nomes e repaginar sistemas antigos (ACOSTA, 2016). 
Importa destacar que as respostas estão carregadas de representações que influem sobre como se dá a relação entre não indígena e indígena no que diz respeito à escuta do sofrimento de algum indígena. Nesta reflexão nos reportamos à Psicologia, uma vez que as análises aqui socializadas referem-se àquelas oriundas dos seminários que aconteceram mais de uma vez no curso de Psicologia, embora as categorias emergentes sejam comuns a outros cursos participantes dos seminários. Por conseguinte, as respostas destacadas foram dadas por quem possivelmente exercerá a profissão de psicólogo.

As representações sociais, segundo Serge Moscovici (2003), são um sistema coletivo de valores, ideias e práticas que possibilitam às pessoas de uma comunidade se comunicarem, pois fornece um código usado para nomear e classificar os aspectos do mundo, assim como da história individual e social daquele grupo. Outra função das representações sociais é a de ordenar o mundo material e social para os indivíduos poderem orientar-se nele, bem como controlá-lo. Elas estabelecem convenções acerca dos objetos com que nos deparamos através de associações com determinada categoria. O autor (MOSCOVICl, 2003, p. 34) afirma que "mesmo quando uma pessoa ou objeto não se adéquam exatamente ao modelo, nós o forçamos a assumir determinada forma, entrar em determinada categoria, na realidade, a se tornar idêntico aos outros, sob pena de não ser nem compreendido, nem decodificado". Há um caráter prescritivo nas representações sociais, porque pensamos através delas, tendo em vista que nascemos dentro de uma estrutura que as impõe como forma de significar o mundo.

Moscovici (2003) considera as representações sociais dinâmicas, no entanto, elas refletem um conhecimento anterior produzido por sucessivas gerações, possuindo um elo com sistemas prévios de imagens. Novas representações emergem de pontos de tensão no sistema representacional. A tensão surge diante do não familiar, da ausência de sentido. Ocorrem, então, dois processos, de acordo com o autor (MOSCOVICl, 2003): objetivação e ancoragem. O primeiro transforma o conceito abstrato produzido por reflexões complexas em um saber mais simples, mais significativo e concreto, baseado em concepções familiares às pessoas. 0 conceito é associado a algo concreto. A ancoragem consiste em incorporar novos elementos de um objeto social em um sistema de categorias familiares e funcionais ao sujeito, pois estão disponíveis em sua memória. Isso insere o objeto dentro da rede de significações que a pessoa dispõe. De certo modo, as representações 
A representação do indígena no discurso de estudantes de Psicologia: possiveis impactos sobre a escuta do sofrimento psíquico indígena

surgem a partir de um processo de familiarização dos conceitos complexos produzidos diante da tensão existente.

O sentido do significante "índio", substantivo imposto pelos colonizadores que definia uma categoria de pessoas, demonstra a potência das redes de significado de atravessarem o tempo sem serem questionadas, quando tais representações configuram realidades que sustentam o status quo de quem ocupa os locais de privilégio dentro da estrutura social. O índio que mora na nossa cabeça, aqui nos valemos do nome do livro de Spensy Pimentel (2012), continuará vivendo lá, caso os pilares de sua morada não sejam derrubados por movimentos sociais indígenas, como o GAln. Por isto, a luta do movimento indígena no Brasil abrange mais que a demanda pela demarcação dos territórios físicos - uma de suas exigências é a possibilidade de manter sua cultura, seu modo de vida, de ser e de conhecer.

O vocábulo "índio" é carregado de significado pejorativo, atrelou-se à ideia de selvagem e primitivo. Ademais, sabemos que "a categoria 'índio' surgiu de equívoco geográfico e homogeneizou arbitrariamente, em sentido claramente empobrecedor, as ricas pluralidade e diversidade das comunidades americanas" (CARBONI; MAESTRI, 2012, p. 76). No entanto, o nome do seminário foi uma escolha dos próprios alunos indígenas, dispostos a debaterem a partir do senso comum e dos preconceitos trazidos à tona pelos participantes dos eventos.

É possível observar no processo de análise dos resultados da pesquisa relacionados ao curso de Psicologia que os preconceitos não apareceram em forma de ódio nas respostas, mas como reificação da ideia do indígena bom selvagem das matas. $O$ indígena como ser humano natural remete à ideia de que a transformação da natureza pelo não indígena coloca o branco fora da natureza. $\mathrm{O}$ indígena, portanto, quando se apropria das tecnologias posteriores àquelas possuídas no momento da chegada dos portugueses, deixa de ser natural; deixa de ser indígena? Não, e há de se ter muito cuidado com tais representações para não se estereotipar os indígenas como alguém que parou no tempo, sem se inserir nas trocas e construções interculturais e se apropriar de tecnologias não inventadas por eles ${ }^{3}$.

\footnotetext{
3 Apenas uma resposta pensou a cultura indígena como não estática: "Ser índio é tentar manter suas tradições ao mesmo tempo que tenta se adaptar à sociedade capitalista tão diferente a sua realidade" (FERNANDES, 2017).
} 
Uma escuta guiada por tal representação pode atrapalhar a prática psicoterapêutica, pois o psicólogo não enxergaria o indígena como um sujeito agente de transformações e em transformação. Se o indígena não for percebido como sujeito, o psicólogo cairá no erro salientado pelo psicanalista Laurence Bataille (1988) de querer que seu desejo seja reconhecido pelo paciente como caminho, em vez de colocar-se em uma posição, dentro da relação transferencial, que possibilite ao paciente indígena ser impelido pelo seu próprio desejo para outro lugar que não Ihe gere sofrimento. O profissional da Psicologia poderia impingir ao paciente indígena seu desejo de mantê-lo fechado ao contato intercultural, objetivando conservar uma cultura e uma identidade supostamente pura.

Profissionais ${ }^{4}$ que fazem a escuta de outra pessoa precisam exercitar a empatia para realizarem movimentos contranarcísicos que os afastem de suas representações e perspectivas com o intuito de abrirem-se para o desconhecido, sem se colocarem como autores da fala e do desejo do outro. É necessário conseguir sair de uma posição de saber-poder para romper práticas e discursos colonizadores, os quais mantêm o outro como tutelado em posição de heteronomia. Deslocar-se dessa posição não significa colocar aquele que se escuta como detentor absoluto do saber-poder, caso contrário, não há possibilidade do diálogo intercultural, necessário para a construção de serviços voltados para o atendimento de indígenas. Na construção de novas possibilidades, toda posição assumida por uma diferença é passível de questionamentos. Escutar envolve equilíbrio, ponderação e comedimento.

A representação de ser humano à parte da sociedade, porque pertencente à natureza, pode lançar o indígena em uma posição de objeto dentro do discurso não indígena, tornando o psicólogo surdo ao desejo de seu paciente, cuja etnia e cultura o profissional pouco ou nada conhece. Desse modo, fazem-se mister conhecimentos pluridisciplinares (História, Antropologia, Geografia etc.) para escutar as alteridades dos indígenas, visando a conhecer as redes de significados que os atravessam e interferem na constituição de seus sujeitos psíquicos.

\footnotetext{
Esta reflexão serve também para aqueles profissionais cuja escuta é parte da instrumentalidade do seu trabalho e, neste caso, para além dos profissionais da psicologia, estão os/as assistentes sociais, uma vez que o GAln é majoritariamente composto por professores do Serviço Social e da Psicologia, assim como estudantes dos referidos Cursos.
} 
A representação do indígena no discurso de estudantes de Psicologia: possiveis impactos sobre a escuta do sofrimento psíquico indígena

Conhecer a cultura e a linguagem possibilita pensar as dinâmicas dos significados e das relações, permitindo analisar elementos manifestos e reprimidos que influem sobre a forma do sofrimento mental. François Laplantine (1998) salienta que nenhum tipo de organização social possui um poder diretamente patogênico, todavia cada sociedade, devido à forma como ordena o mundo, provoca alterações na estrutura, na economia e, principalmente, no conteúdo dos quadros clínicos psicopatológicos. A frequência e a maneira como são percebidas e toleradas as psicopatologias também sofrem influência da cultura de cada povo, ou etnia. Alterações nas dinâmicas socioculturais, como o maior contato entre etnia indígena e sociedade envolvente, pode causar variações nos quadros clínicos. Um não indígena nunca conseguirá compreender todas as nuances da diferença existente no sujeito indígena que escuta, porém o esforço de abrir-se é necessário, no intento de compreender o funcionamento do outro mais profundamente, sem prender-se a aplicações automáticas de modelos teóricos ocidentais preponderantes na Psicologia.

Com vistas a evitar que o trabalho do psicólogo contribua com os epistemicídios (SANTOS, 2010) das culturas indígenas, ou seja, com a destruição de paradigmas de construção de conhecimentos distintos do acadêmico-científico ocidental, quem faz a escuta precisa adotar uma metodologia não colonizadora, que preze pelo dialogismo. Ademais, a assunção de uma postura decolonial (MIGNOLO, 2010) exige não o abandono dos conhecimentos existentes, mas a ruptura com mecanismos cognitivos que induzam a uma racionalidade colonial, ou seja, é preciso usar os conhecimentos acadêmico-científicos de uma maneira crítica e aberta a outras epistemologias para se construir novos conhecimentos e práticas que abranjam as diferenças.

Rafaela Achatz et al. (2016), ao falar sobre a prática e a pesquisa na Rede de Atenção à Pessoa Indígena, vinculada ao Departamento de Psicologia Experimental do Instituto de Psicologia da Universidade de São Paulo, afirma a importância de uma perspectiva dialógica para o funcionamento do serviço. A formação de vínculo através do dialogismo implica em não reduzir o outro a conhecimentos prévios que possuímos, pois a tentativa de traduções de saberes alheios pode acarretar a ampliação de distâncias em vez de reais aproximações. Desse modo, não há a pretensão de compreender completamente a alteridade, nem de colocá-la como semelhante. Mantém-se o outro como outro, reconhecendo a existência de mis- 
térios, o que alimenta a demanda pela escuta e pelo diálogo, assim como evita uma relação verticalizada, na qual o psicólogo se coloque como detentor de um saber a ser prescrevido.

A despeito da persistência do mistério, concordamos com Lucila Gonçalves (2016, p. 226), psicanalista membro do subnúcleo Psicologia e Povos Indígenas do CRP-SP, que, na encruzilhada dos encontros, "talvez seja a atitude de abertura e compaixão com o outro que faz com que eu possa tocá-lo sem me confundir com ele; que faz com que eu possa conhecê-lo sem me projetar". A comunicação baseada em abertura ao outro, levando em consideração nossa experiência como membros do GAIn e monitor/orientadora das estudantes indígenas, junto do afeto sincero, possibilita o verdadeiro encontro intercultural, no qual a interrogação única de cada diálogo específico abre espaço para uma escuta sem encaixes automáticos em estereótipos teóricos ou estigmatizações sociais. A monitoria, realizada pelos estudantes não indígenas e professoras orientadoras, possibilita a nossa percepção e construção de vínculos sem nos confundirmos nem nos projetarmos em quem acolhemos e acompanhamos.

Assim, considerando o que vimos até aqui, nós nos aproximamos da discussão sobre o interculturalismo, que se diferencia do multiculturalismo, pois vai além da constatação da coexistência de culturas ou da ambição de estabelecimento de uma supercultura universal apta a fornecer respostas universais (SILVEIRA PETTER DAMÁZIO, 2008). Em vez disso, exige um tratamento igualitário entre as culturas, opondo-se a imperialismos. Contrário a hegemonias, o interculturalismo salvaguarda os direitos de cada cultura sem o intuito de preservá-las intactas ao contato. A troca simbólica ocorre em ambos os sentidos no decorrer das interações culturais, provocando alterações bilaterais (SILVEIRA PETTER DAMÁZIO, 2008).

Somente por um viés intercultural é possível escutar uma estudante kaingang dizer que, agora, o "conhecimento é nossa flecha" e que seu futuro será exercer

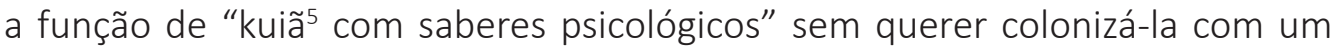
olhar que a coloque em uma categoria estática e isolada, proibida de mudar. $\mathrm{O}$ contato interétnico gera trocas culturais por via da fronteira permeável que deli-

\footnotetext{
5 "Kuiã" é a figura xamânica da cultura kaingang, capaz de realizar a interlocução com os espíritos da natureza, intermediando a relação entre mundo material e espiritual. Conhecedor de saberes de cura físico-mental-espiritual.
} 
mita a identidade, permitindo a transformação de alguns caracteres e impedindo a alteração de outros traços, encarados como âncoras identitárias (POUTIGNAT; STREIFF-FENART, 2011). Monitoramos essa provável futura kuiã com saberes psicológicos. Escutamos seus dilemas sobre como poderia aplicar os conhecimentos de Psicologia em sua aldeia e reconhecemos as potencialidades que ela tem para adequar ferramentas teóricas com o objetivo de pensar a saúde mental e espiritual de sua etnia. Essa adaptação do conhecimento acadêmico à sua cultura e os questionamentos que levanta durante os debates em sala de aula são exemplos e parte daquilo que entendemos sobre a interculturalidade.

A saúde indígena atrela-se à vivência de sua cultura, comunidade e identidade, isso fica claro, por exemplo, na reivindicação feita pelos estudantes indígenas da UFRGS de uma casa do estudante específica para indígenas, onde possam morar, enquanto cursarem a universidade, fora de suas aldeias, porém sem perder o contato com seus costumes e com seus estilos de vida comunitários. A demanda pela vivência de suas culturas não implica ausência de apropriação de traços culturais e tecnologias da sociedade envolvente, sendo a apropriação do conhecimento acadêmico considerada pelos estudantes indígenas uma ferramenta de sobrevivência dos seus costumes diante das contendas político-territoriais.

Conhecer a legislação e os princípios que norteiam o sistema jurídico brasileiro, por exemplo, é relevante para resistir a ataques conservadores, que tolhem direitos e discriminam, por isso o Direito tem sido um dos cursos escolhidos pelas lideranças em alguns concursos vestibulares. Os indígenas não são os inocentes infantis consoantes à antiga figura imaginária do bom selvagem, pelo contrário, tal como uma das respostas do seminário diz, "ser indígena é fazer parte de um povo que tem uma cultura rica, com suas tradições, línguas próprias, ritos e crenças, e que luta pra manter viva essa cultura dentro de uma realidade social que exclui, segrega e estigmatiza as minorias" (FERNANDES, 2017).

\section{ESCUTAR AS DIFERENÇAS INDÍGENAS}

Alguns estudantes de Psicologia levantaram a questão da diferença cultural e de uma estrutura interna específica: "Eu acho que... É nascer em uma cultura diferente da minha, ter crenças próprias, uma estrutura interna diferente"; "Ser índio é viver uma cultura diferenciada entre outras no nosso mundo, um padrão 
de vida que explora atividades da mata e que vivem em conjunto onde todos são um"; "O que é ser índio. É ser homem, mulher, criança, idoso na sua cultura e ter uma cultura diversa da sua nos seus contatos diários" (FERNANDES, 2017). A representação do indígena num lugar de diferença, tanto na cultura quanto na constituição do sujeito psíquico indígena, pode ser sinal de uma sensibilidade para escutar vozes dissonantes, cujas falas seguem outras lógicas.

É necessário buscar conhecimento sobre a cultura do outro para se fazer uma boa escuta, caso contrário, os detalhes dos significados escapam. O psicólogo de etnia Xukuru, Edinaldo dos Santos Rodrigues (2016), graduado pela UFSCAR, no intento de responder à pergunta sobre o que fazer depois de formado em Psicologia junto aos povos indígenas, diz que, malgrado seja uma resposta ainda em construção,

[...] já podemos apontar caminhos possíveis a começar com o respeito e apoio às lutas dos povos indígenas. Na prática psi, técnica e política precisam caminhar juntas; ter um olhar diferenciado para concepções sobre a saúde e doença e, principalmente, compromisso ético para apoiar e respeitar os saberes tradicionais, principalmente no diálogo com os pajés e outros detentores dos saberes indígenas no que diz respeito à saúde mental. (RODRIGUES, 2016, p. 233-4).

O rompimento das barreiras epistemológicas por via do diálogo pode evitar o atendimento prestado de maneira problemática às populações indígenas pelas equipes de saúde indígena e equipes de atenção básica, conforme Rodrigues (2016). O autor relata que, diante do sofrimento mental dos pacientes indígenas, os profissionais costumam encaminhá-los para atendimentos psiquiátricos, cujas práticas se baseiam em diagnosticar e receitar medicamentos psicotrópicos, aumentando a dependência de remédios nas aldeias sem combater as causas psicossociais (pobreza, conflito por terras, perda de parentes etc.) do sofrimento.

Como parte da revisão de literatura sobre a escuta por parte do profissional psicólogo, alguns estudos enriquecem esta reflexão, como o realizado por Elisabeth Pastore (2016), psicóloga social e clínica com experiência na atenção ao povo indígena Kaxixó, que relata os usos que encontrou para a Psicologia ao deparar-se com as demandas das aldeias: fazer a escuta do sofrimento psíquico provocado pela violação de direitos, pelas perseguições, pelos assassinatos, pelas expropriações de terras, pelo luto das sucessivas perdas dos mais velhos e dos lugares de memória; fazer a mediação das tensões nas relações pessoais e grupais 
internas, ou externas ao grupo. Lucila Gonçalves (2016) propõe outras formas de atuação do psicólogo na atenção ao indígena: ajudar na capacitação dos recursos afetivos das equipes de saúde, assim como na criação de espaços de discussão e fazer-junto envolvendo aldeia e profissionais de saúde.

O medo, por parte dos indígenas, de uma prática psiquiátrica etnocêntrica aparece, também, nos relatos das estudantes indígenas que acompanhamos. No momento do debate da escolha dos cursos em que haveria reservas de vaga para indígenas, as estudantes indígenas escutaram lideranças de aldeias afirmarem que o curso de Psicologia não deveria ser escolhido, pois poderia levar a loucura branca para dentro das aldeias. Entendemos que é exatamente esta percepção das lideranças indígenas sobre o curso de Psicologia que deve ser trazida para discussão sobre a formação profissional e a importância da escuta das diferenças, para que os modos de ser, viver e conhecer dos indígenas sirvam como base para discussão de um currículo que seja capaz de acolher estas diferenças e primar pelas vivências interculturais. Tal aprimoramento do currículo pode contribuir para transformar as representações carregadas pelos alunos não indígenas sobre os indígenas, possibilitando aos futuros psicólogos um refinamento da escuta das alteridades.

O diálogo intercultural consolidado no GAln e nas monitorias respeita o lugar de fala - perspectiva, de acordo com os marcadores sociais da diferença, de onde um sujeito se expressa - e o lugar de dor - a dor sentida pelo sujeito sofre influência dos marcadores sociais da diferença que o atravessam (TIBURI, 2017). Os distintos lugares de fala propiciam o debate intercultural das diferentes compreensões de mundo, sem silenciamentos de nenhum dos lados. O lugar de dor cobra uma outra postura, voltada para a escuta, não para o debate. O GAIn e a monitoria exercitam a escuta do sofrimento de etnias nas quais a Psicologia inexiste como área de conhecimento, estando a saúde mental, em suas culturas, ligada à saúde espiritual sob os cuidados dos xamãs. O lugar de dor, diferentemente do lugar de fala, não é discutível, devemos tentar compreender e colaborar com o trabalho de elaboração dessa dor pelo sujeito indígena. Essa sensibilização da escuta da alteridade era uma das metas das estudantes indígenas durante os seminários na graduação de Psicologia.

Fazer a escuta dos kaingangs exige que se leve em conta sua epistemologia, na qual a razão não é hierarquicamente superior ao espírito. Há uma outra 
estrutura de pensamento e conhecimento a ser considerada, tal como outra rede de significados, o que torna difícil a análise para quem não as compartilha. Daniel Munduruku (2009) declara que as palavras dos indígenas devem ser escutadas com um ouvido mais próximo do coração do que da razão. Caso contrário, damos um exemplo prático: como analisar a interação entre o sujeito kaingang e um espírito do mato? Para o ouvido de um psicólogo encerrado em sua epistemologia, isso poderia ser um sinal de esquizofrenia ou de um surto psicótico.

Uma das respostas coletadas nos seminários destaca que ser índio é "Vivere perceber a vida a partir de outro ângulo". Diante dessa diferença, a percepção do psicólogo do sofrimento existente também deve partir de outro ângulo que leve em consideração o marcador social da diferença da etnia e todos os atravessamentos implicados. Classificação produzida socialmente, os marcadores categorizam os indivíduos, identificando-os em determinado nível com uma posição de privilégio/ desvantagem social, o que acaba por influir sobre a organização das vivências de cada um (ZAMBONI, 2014). As diferenças simbólicas entre etnias afetam inclusive as noções de normal e patológico, não sendo patológica a comunicação com os espíritos do mato entre os kaingang.

\section{CONSIDERAÇÕES FINAIS}

Estas reflexões - entremeadas por análises de resultados da pesquisa e relatos de experiência, duas coisas que não se apartam na subjetividade de pesquisadores-escritores - não seriam possíveis se não tivéssemos vivenciado as experiências de extensão por meio dos seminários "O que é ser índio?" e do desenvolvimento de uma pesquisa documental, assim como da monitoria e orientação de estudantes indígenas. Definimos como foco para este artigo as respostas que emergiram nos seminários do curso de Psicologia, as quais propiciaram conteúdo para reflexões sobre a questão do sofrimento do coletivo indígena que acessa a educação superior e sobre a escuta da diferença por parte de profissionais da Psicologia.

Entretanto, a escuta não é condição sine qua non da Psicologia, pois se trata de uma premissa das relações humanas e sociais, mas, sem dúvida, o desenvolvimento das competências técnicas e relacionais para a escuta como parte do trabalho do psicólogo é fundamental. Cabe destacar que os autores que se 
mobilizaram nesta tecitura são estudantes indígenas e não indígenas do curso de Psicologia em conjunto com uma pesquisadora e professora do curso de Serviço Social, o que demonstra a possibilidade de articulação de conhecimentos, respeitando as particularidades do campo da Psicologia trazido pelos estudantes. Assim sendo, como o sofrimento se sobressaiu nos escritos dos estudantes da Psicologia quando questionados sobre o que é ser índio, nada mais coerente do que propormos essas reflexões.

A presença das estudantes indígenas no curso de Psicologia da UFRGS (ou ainda na instituição como um todo) tem provocado movimentos, num plano micropolítico, tal como o aparecimento de questões étnicas e indígenas nas discussões de algumas disciplinas. As ações ainda são embrionárias, mas abrem brecha para uma conscientização sobre a diferença e sobre como trabalhar com ela de um modo não colonizador.

Pessoas atravessadas por marcadores sociais da diferença distintos do perfil predominante dos universitários estão trazendo novos debates para dentro das salas de aula e campos profissionais. A Psicologia não escapa disso. Lidar com as diferenças, dentro do campo psicológico acadêmico ou profissional depende de adaptações e inovações de conhecimentos, visando a uma maior pluralidade, assim como à quebra de representações embasadas em sensos comuns colonizados como algumas que apresentamos no decorrer do texto. Ampliar as oportunidades de encontros entre as diferenças é de suma importância. Abrir-se ao diálogo intercultural é um caminho para desconstruir uma escuta colonizadora e fazer da Psicologia uma ferramenta útil para diferentes raças e etnias.

\section{REFERÊNCIAS}

ACHATZ, Rafaela Waddington; SOUSA, Flaviana Rodrigues; BENEDITO, Marília Antunes; GUIMARÃES, Danilo Silva. Considerações sobre o trabalho com comunidades indígenas a partir do serviço "rede de atenção à pessoa indígena". In: CONSELHO REGIONAL DE PSICOLOGIA DE SÃO PAULO. Povos indígenas e psicologia: a procura do bem viver. São Paulo: CRP-SP, 2016. p. 189-98.

ACOSTA, Alberto. O bem viver: uma oportunidade para imaginar outros mundos. São Paulo: Autonomia Literária: Elefante, 2016.

BATAILLE, Laurence. O umbigo do sonho. Por uma prática da Psicanálise. Rio de Janeiro: Zahar, 1988. 
BRASIL. Lei n. 12.711, de 29 de agosto de 2012. Dispõe sobre o ingresso em universidades federais e instituições federais de ensino técnico de nível médio. Brasília, 2012.

CAMINHA, Pero Vaz de. A carta de Pero Vaz de Caminha: reprodução fac-similar do manuscrito com leitura justalinear, de Antônio Geraldo da Cunha, César Nardelli Cambraia e Heitor Megale. São Paulo: Humanitas, [1500]1999

CARBONI, Florence; MAESTRI, Mário. A linguagem escravizada: língua, história, poder e luta de classes. São Paulo: Expressão Popular, 2012.

FERNANDES, Rosa Maria Castilhos. Contribuições para afirmação dos direitos indigenistas no ensino superior: uma experiência de extensão e pesquisa na UFRGS. Projeto de Pesquisa. Porto Alegre: UFRGS, 2017.

FERNANDES, Rosa Maria Castilhos; AMES, Valesca; DOMINGOS, Angélica. Encontros e desencontros das ações afirmativas no ensino superior: as resistências dos estudantes indígenas. O Social em Questão, Porto Alegre, RS, ano XX, n. 37, p. 71-90, jan./abr. 2017.

GONÇALVES, Lucila de Jesus M. Psicologia e povos indígenas: encontros na encruzilhada. In: CONSELHO REGIONAL DE PSICOLOGIA DE SÃO PAULO. Povos indígenas e psicologia: a procura do bem viver. São Paulo: CRP-SP, 2016. p. 217-26.

HALL, Stuart. Da diáspora: identidades e mediações culturais. Liv Sovik (Org.). Belo Horizonte: Editora da UFMG, 2013.

LAPLANTINE, François. Aprender Etnopsiquiatria. São Paulo: Brasiliense, 1998.

MIGNOLO, Walter D. "Aiesthesis decolonial”. Calle 14, v. 4, n. 4, p. 10-25, jan./jun. 2010.

MOSCOVICl, Serge. Representações sociais: investigações em psicologia social. Petrópolis, RJ: Vozes, 2003.

MUNDURUKU, Daniel. Banquete dos deuses: conversa sobre a origem da cultura brasileira. São Paulo: Global, 2009.

NINHPRYG, Angélica Domingos. O bem viver Kaingang: perspectivas de um modo de vida para construção de políticas sociais com os coletivos indígenas. 2016. Trabalho de Conclusão de Curso (Graduação em Serviço Social) - Universidade Federal do Rio Grande do Sul. Porto Alegre, RS, 2016.

ORGANIZAÇÃO DOS ESTADOS AMERICANOS. Declaração americana sobre os direitos dos povos indígenas. Santo Domingo, República Dominicana: OEA Documentos Oficiais, 2016. 
A representação do indígena no discurso de estudantes de Psicologia: possiveis impactos sobre a escuta do sofrimento psíquico indígena

PASTORE, Elisabeth Passero. Psicologia e povos indígenas: reflexões iniciais sobre a participação do psicólogo na construção do plano de gestão territorial e ambiental da terra indígena Kaxixó In: CONSELHO REGIONAL DE PSICOLOGIA DE SÃO PAULO. Povos indígenas e psicologia: a procura do bem viver. São Paulo: CRP-SP, 2016. p. 209-16.

PIMENTEL, Spensy. O índio que mora na nossa cabeça. São Paulo: Prumo, 2012.

POUTIGNAT, Philippe; STREIFF-FENART, Jocelyne. Teorias da etnicidade: seguido de grupos étnicos e suas fronteiras de Fredrik Barth. São Paulo: Ed. UNESP, 2011.

RODRIGUES, Edinaldo dos Santos. O lugar da psicologia nas questões indígenas. In: CONSELHO REGIONAL DE PSICOLOGIA DE SÃO PAULO. Povos indígenas e psicologia: a procura do bem viver. São Paulo: CRP-SP, 2016. p. 227-34.

SANTOS, Boaventura de Souza. Para além de um pensamento abissal: das linhas globais a uma ecologia de saberes. In: SANTOS, Boaventura de Sousa; MENESES, Maria Paula (Org.). Epistemologias do sul. São Paulo: Cortez, 2010.

SILVEIRA PETTER DAMÁZIO, Eloise da. Multiculturalismo versus interculturalismo: por uma proposta intercultural do Direito. Desenvolvimento em Questão, Ijuí, RS, v. 6, n. 12, p. 63-86, jul./dez. 2008.

TIBURI, Márcia. Lugar de fala e lugar de dor. Revista Cult, São Paulo, mar. 2017 Disponível em: https://revistacult.uol.com.br/home/lugar-de-fala-e-etico-politica-da-luta/. Acesso em: 22 jun. 2018.

ZAMBONI, Marcio. Marcadores sociais. Sociologia Especial, São Paulo, 2014. Disponível em: https://assets-dossies-ipg-v2.nyc3.digitaloceanspaces.com/sites/2/2018/02/ ZAMBONI_MarcadoresSociais.pdf. Acesso em: 6 mar. 2016.

\section{Sobre os autores:}

Rafael Filter Santos da Silva: Mestre em História e graduando em Psicologia pela Universidade Federal do Rio Grande do Sul (UFRGS). E-mail: rafilter1988@gmail.com, Orcid: http://orcid.org/0000-0002-9391-6733

Rosa Maria Castilhos Fernandes: Doutora em Serviço Social pela Pontifícia Universidade Católica do Rio Grande do Sul (PUCRS). Professora do PPG de Serviço Social da Universidade Federal do Rio Grande do SUL (UFRGS). E-mail: rmariacf@uol.com.br, Orcid: http://orcid.org/0000-0001-5499-714X 
Rejane Nunes de Carvalho: Aluna indígena no curso de Psicologia da Universidade Federal do Rio Grande do Sul (UFRGS).E-mail: rejane06carvalho@hotmail.com, Orcid:https://orcid.org/0000-0003-4213-8625

Recebido em 15 de janeiro de 2019

Aprovado para publicação em 11 de abril de 2019 